Supporting Information - Part 2:

\title{
METHOX - a New Pyridine $N$-Oxide Organocatalyst for the Asymmetric Allylation of Aldehydes with Allyltrichlorosilanes
}

Andrei V. Malkov, ${ }^{*}$ Mark Bell, Fabiomassimo Castelluzzo, and Pavel Kočovský * Department of Chemistry, University of Glasgow, Glasgow G12 8QQ, U.K. amalkov@chem.gla.ac.uk; p.kocovsky@chem.gla.ac.uk

Table of Contents

${ }^{1} \mathrm{H}$ and ${ }^{13} \mathrm{C}$ NMR spectra of key compounds (10-12, 16b,c, and 17a-c) $\quad \mathrm{S}(2) 2-\mathrm{S}(2) 18$ 
$\mathrm{S}(2) 2$

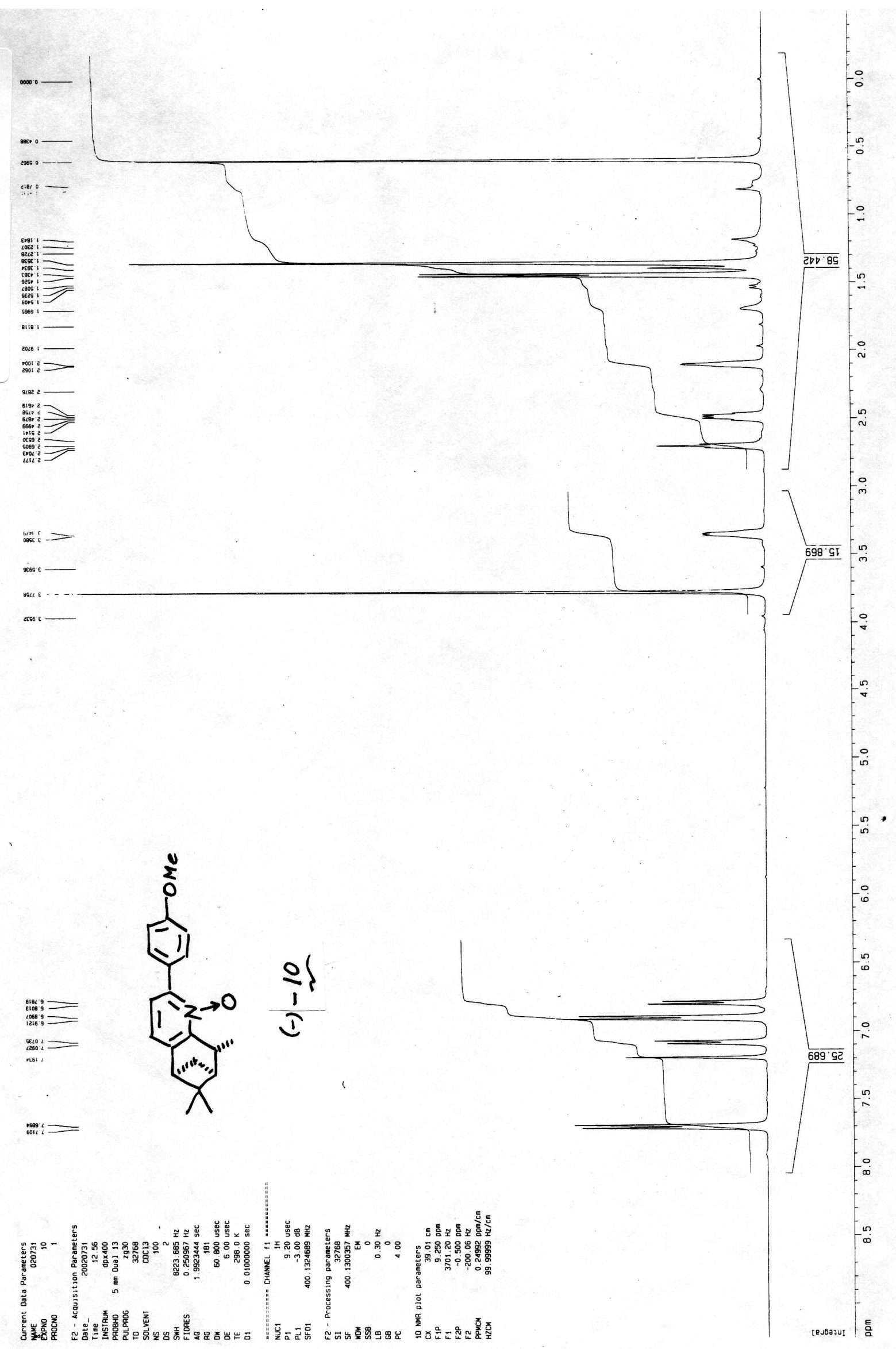


S(2) 3

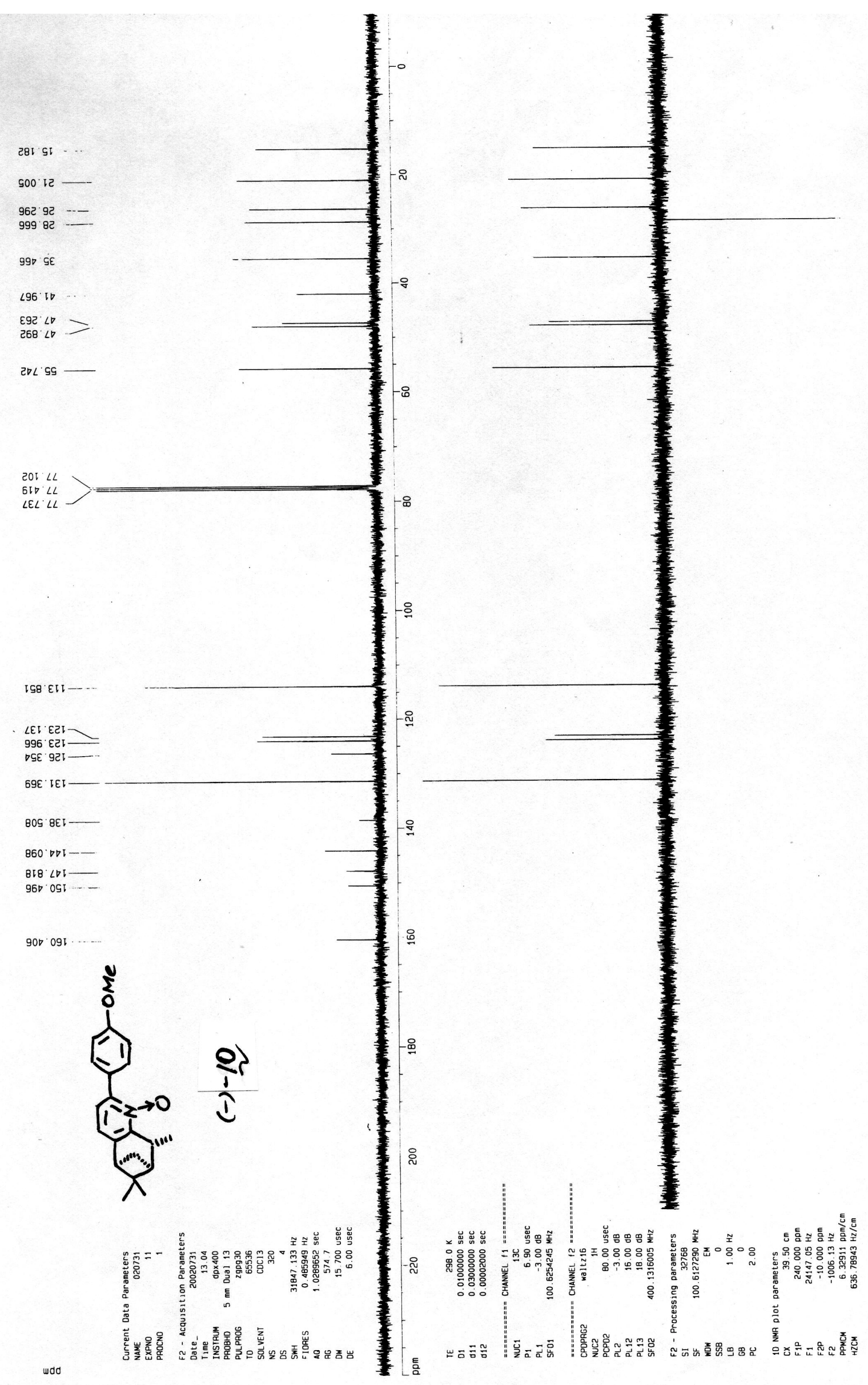


S(2) 4
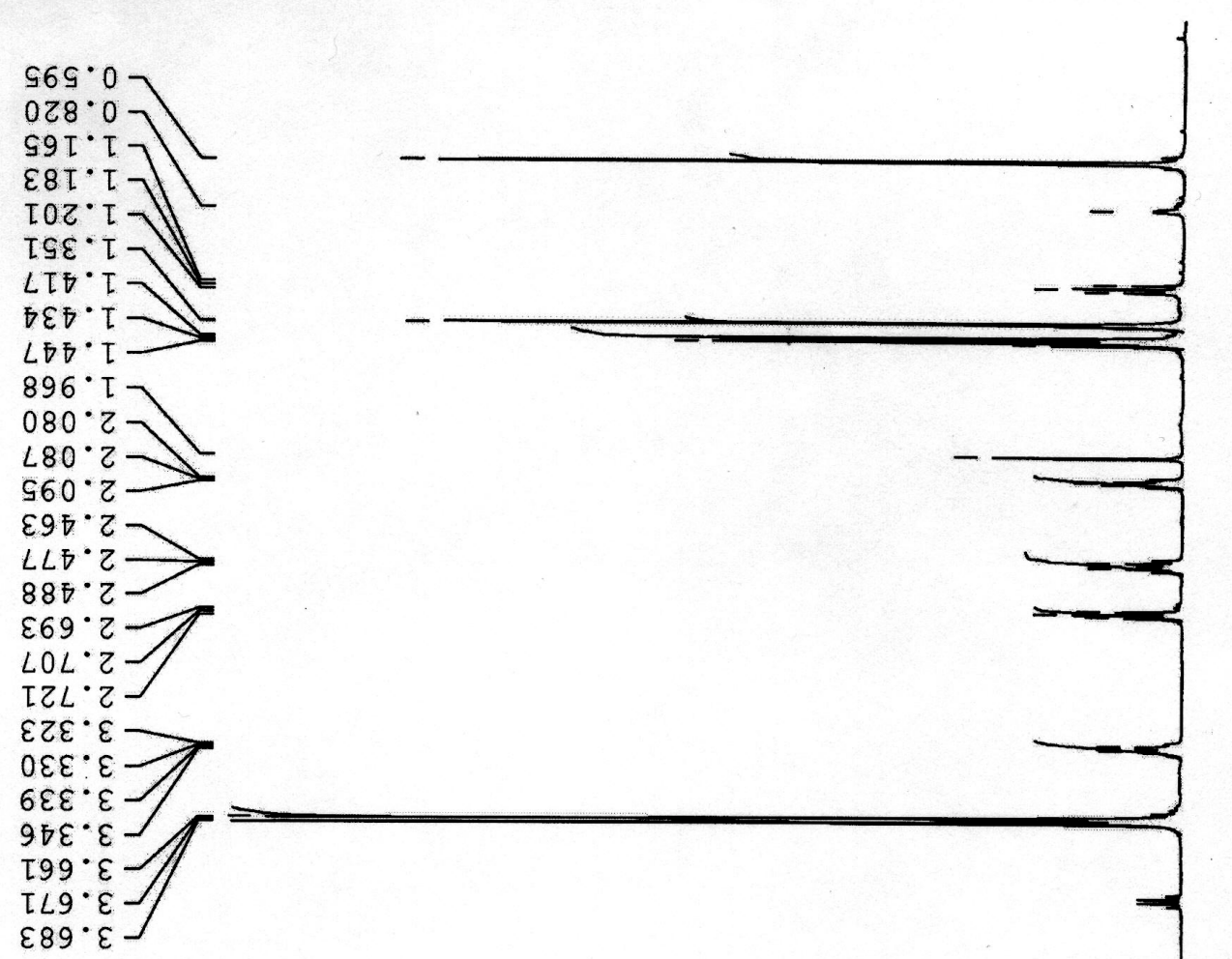

영

!n

$\therefore=6 \varepsilon 0^{\circ} \varepsilon$

- ㅇ.

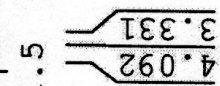

.

$i=\lcm{286^{\circ} 0}$

$\stackrel{\angle \nabla 0 \cdot \tau}{\sim}$

$\longdiv { 9 8 6 ^ { \circ } 0 }$

ㅇ.

m

in $\overline{6 L 6^{\circ} 0}$

$m$

$00 \varepsilon \cdot 9$

$=0$

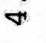

?

$\circ$

in

«?

in

$\stackrel{0}{\circ}$

$8 \varepsilon 5 \cdot 9$

LSS.

$9 L S \cdot 9$

$9 S L: 9 \square$

SE6.

口५6.9

$56 T^{\circ} L$

$\angle E Z^{\circ} L$

$852 \cdot L$

$6 L Z \cdot L$
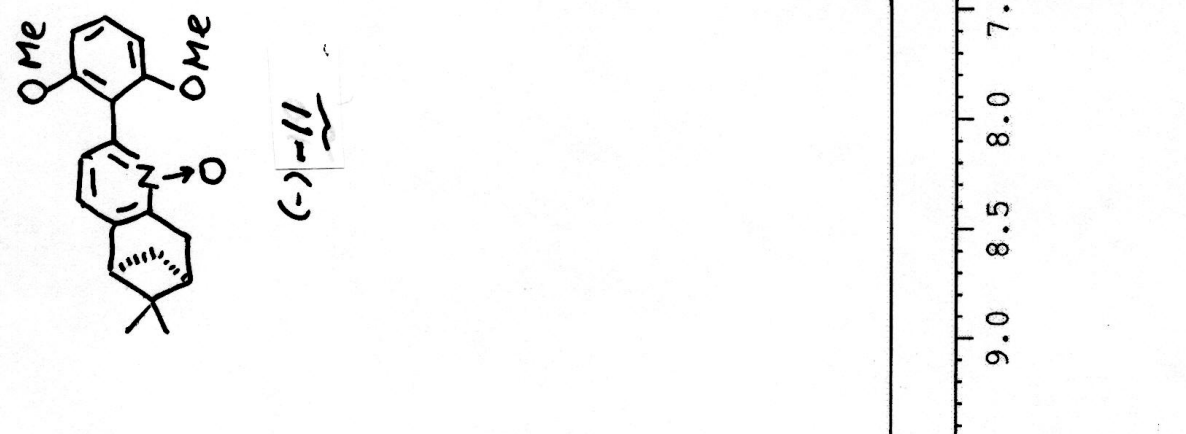


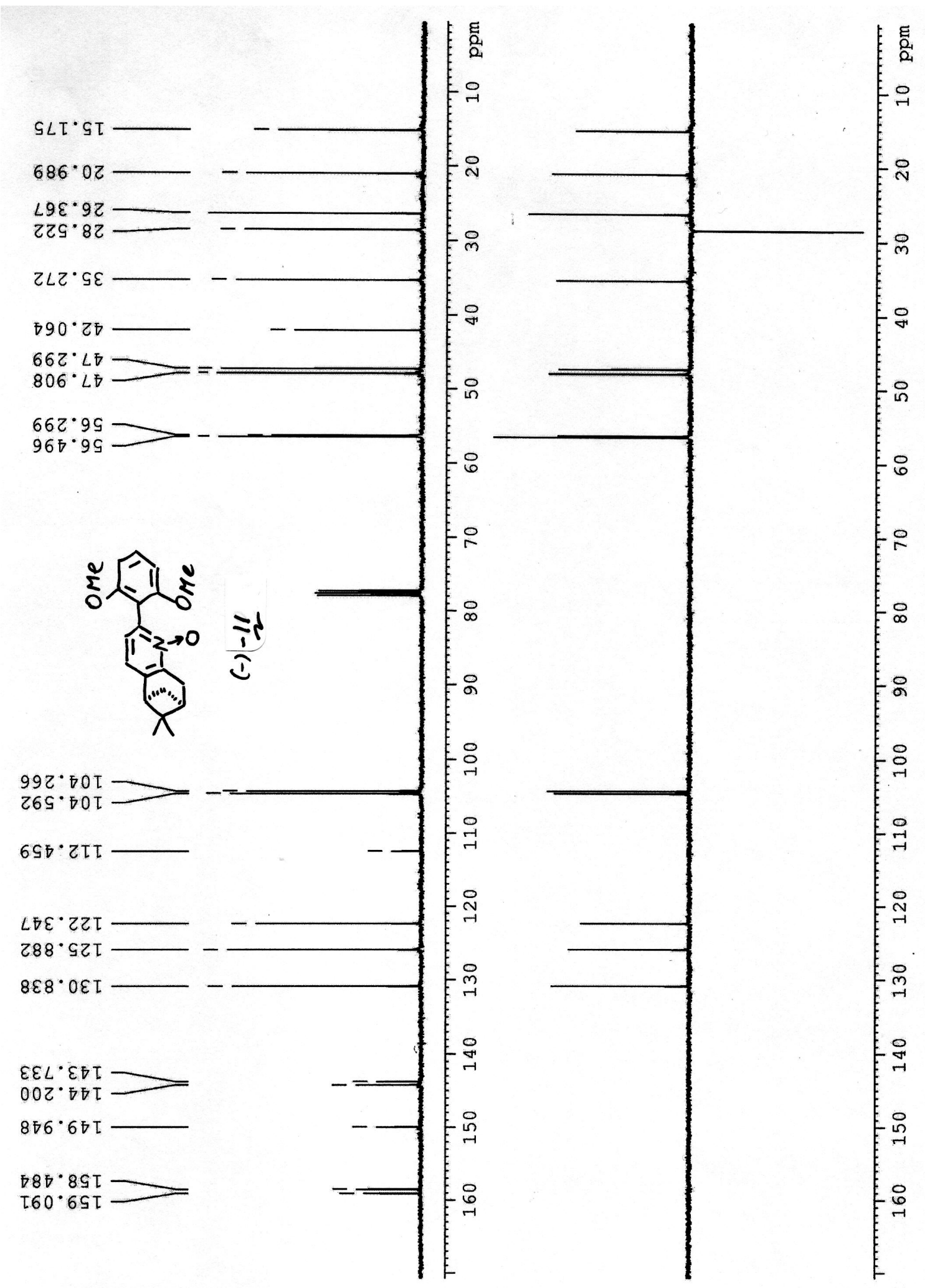


S(2) 6

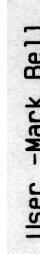
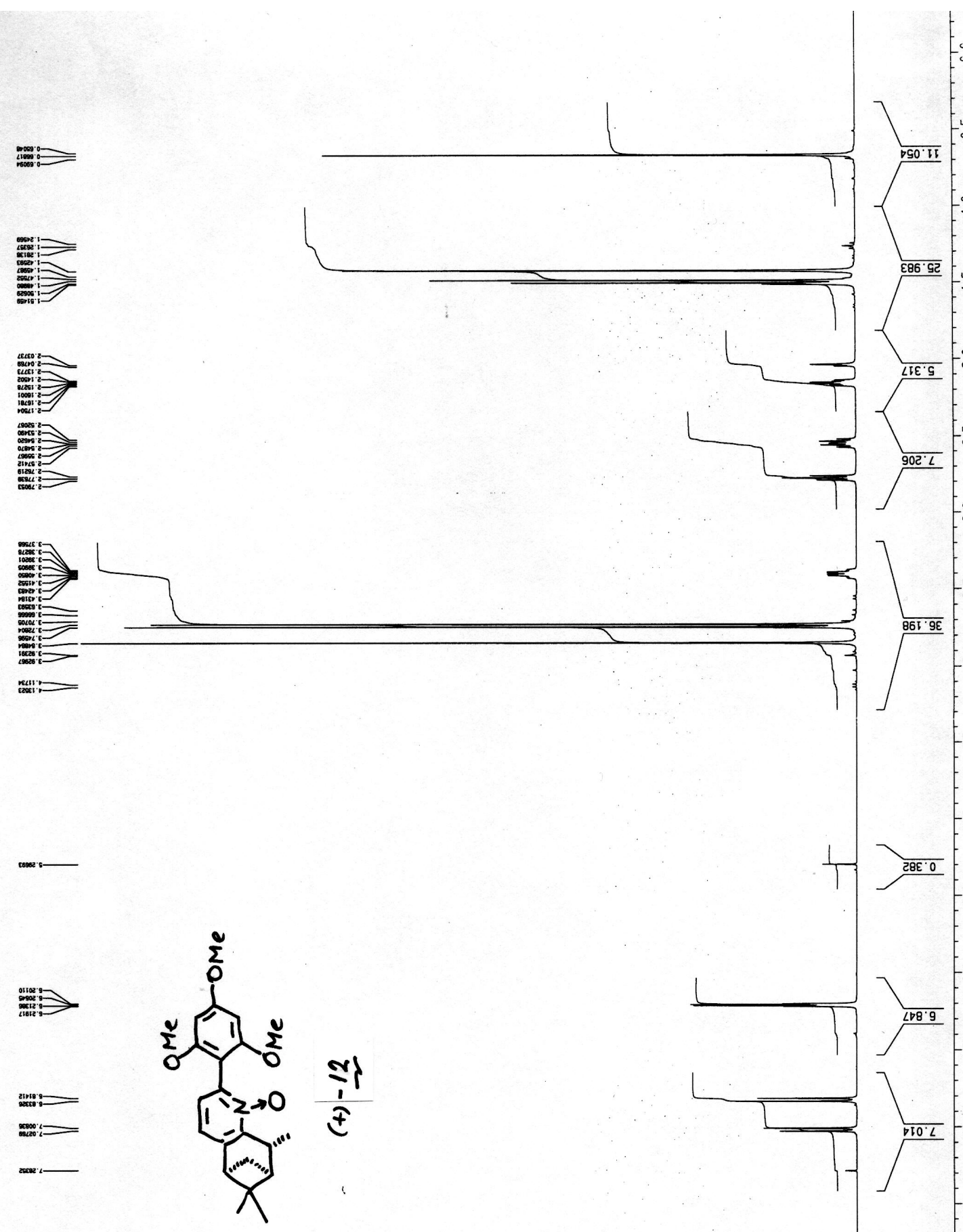

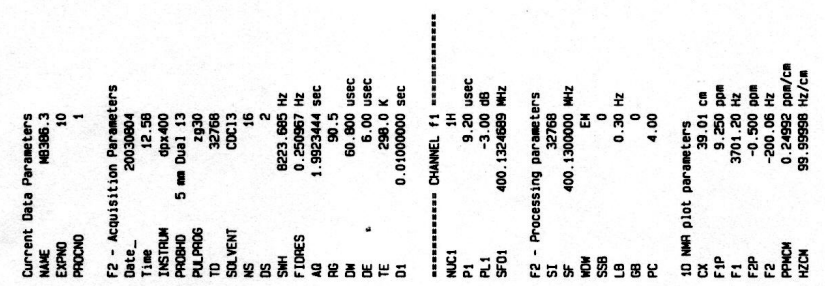

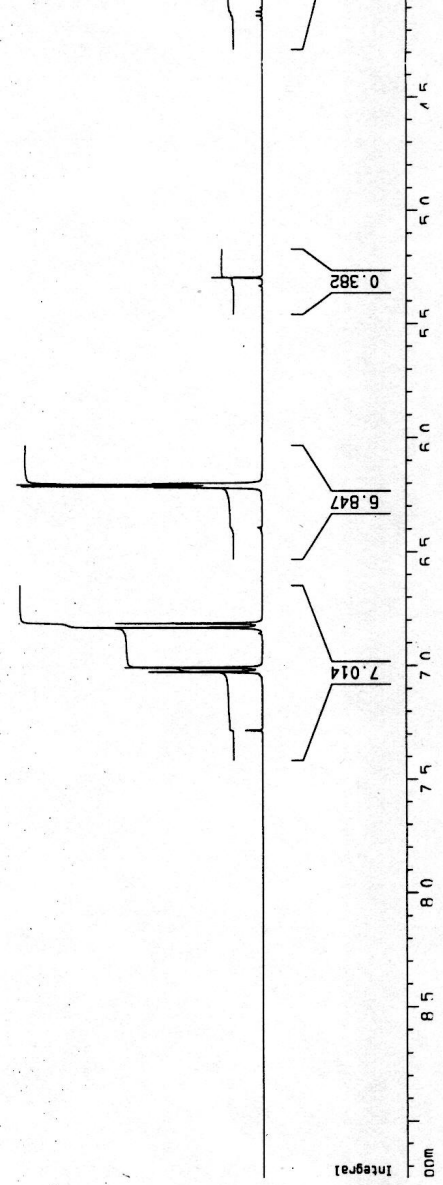


$\mathrm{S}(2) 7$

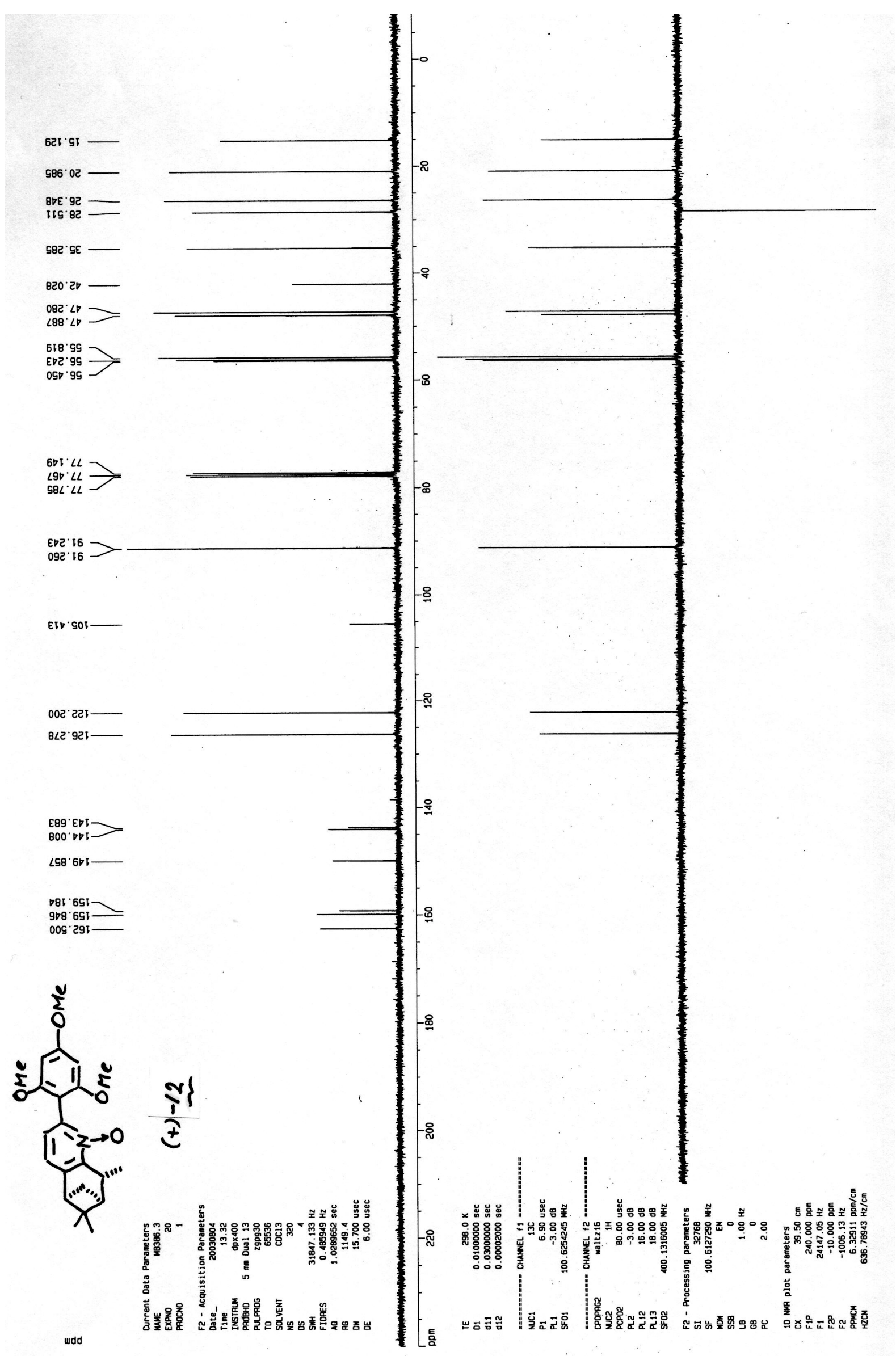


S(2) 8
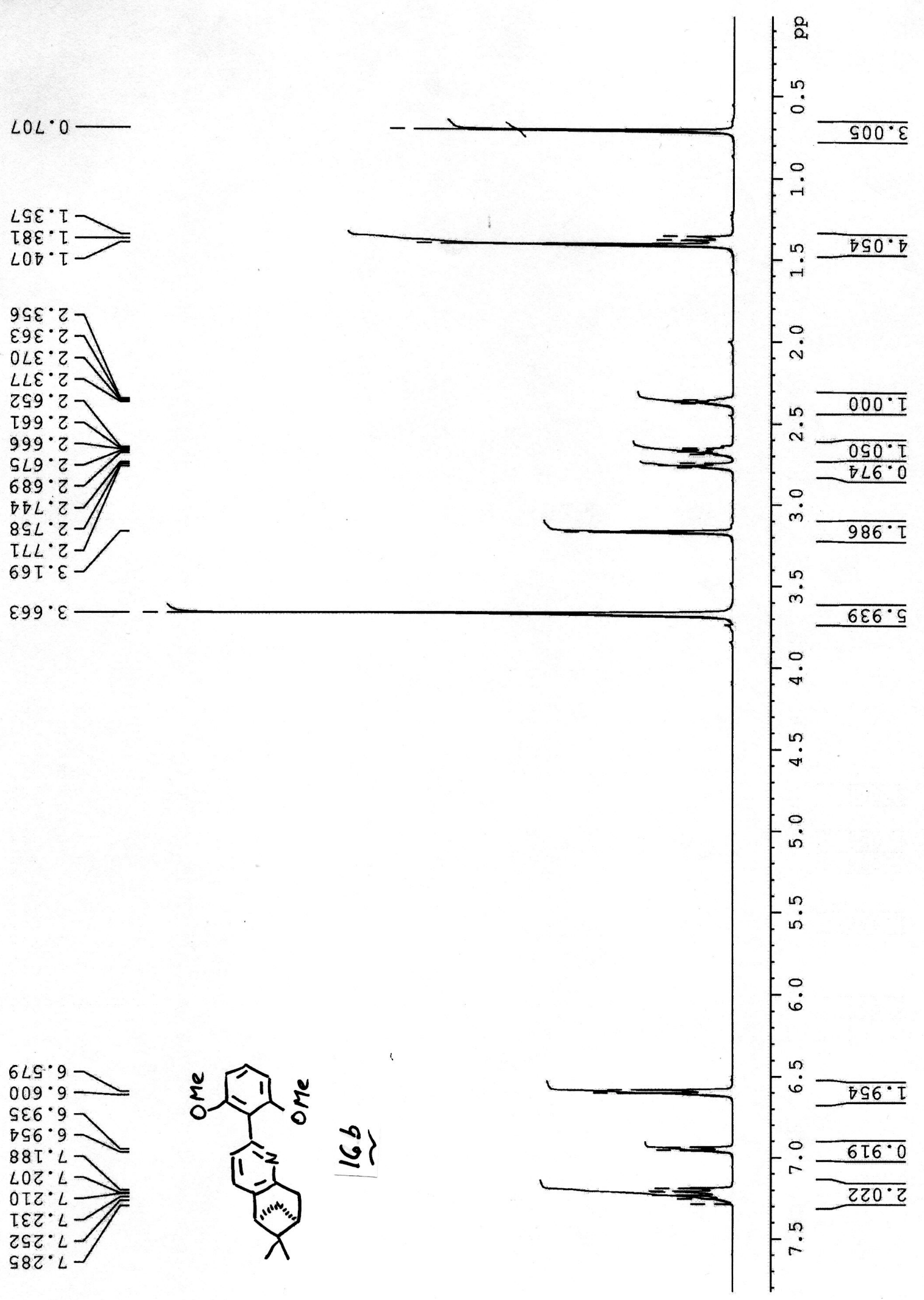
S(2) 9

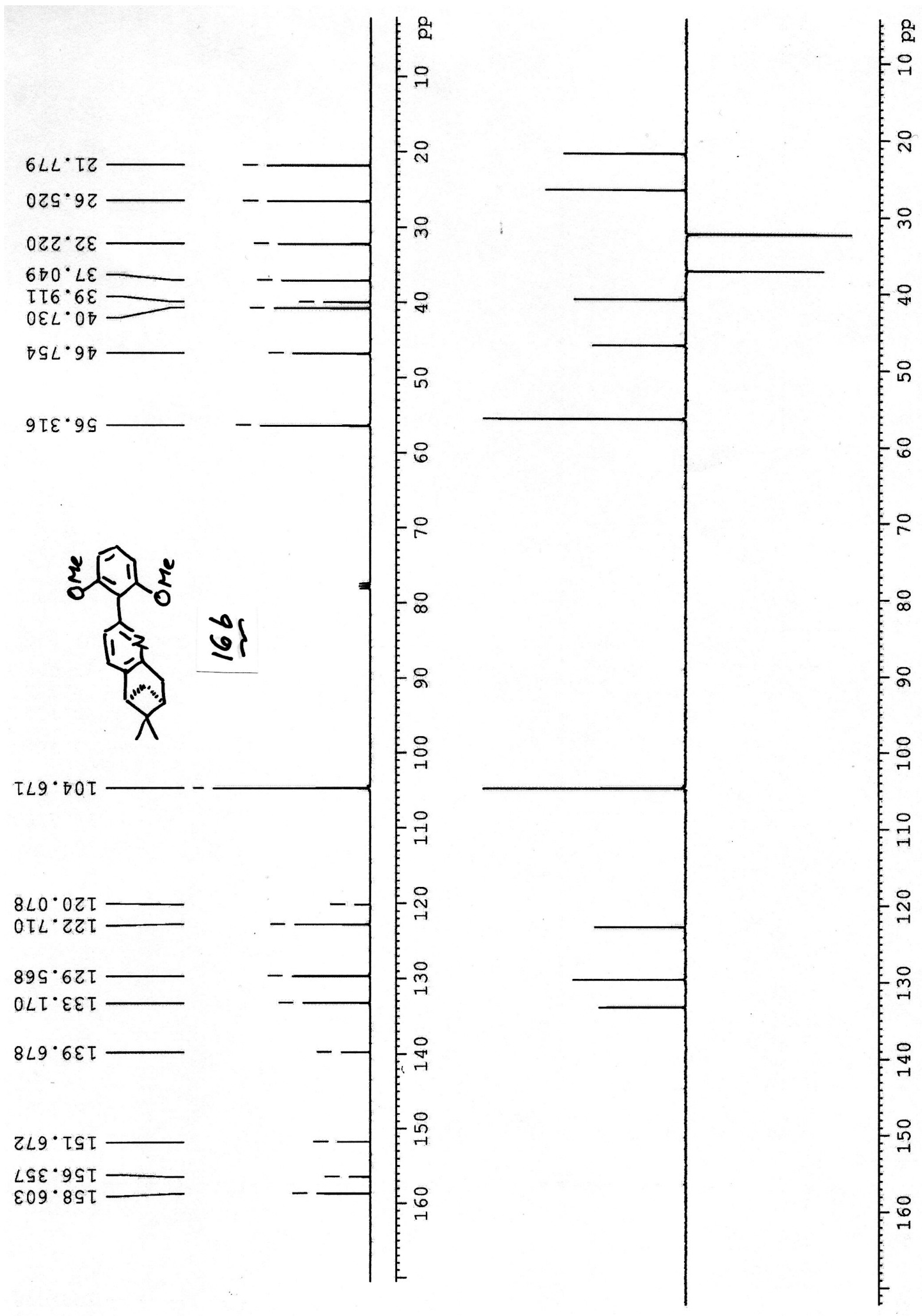




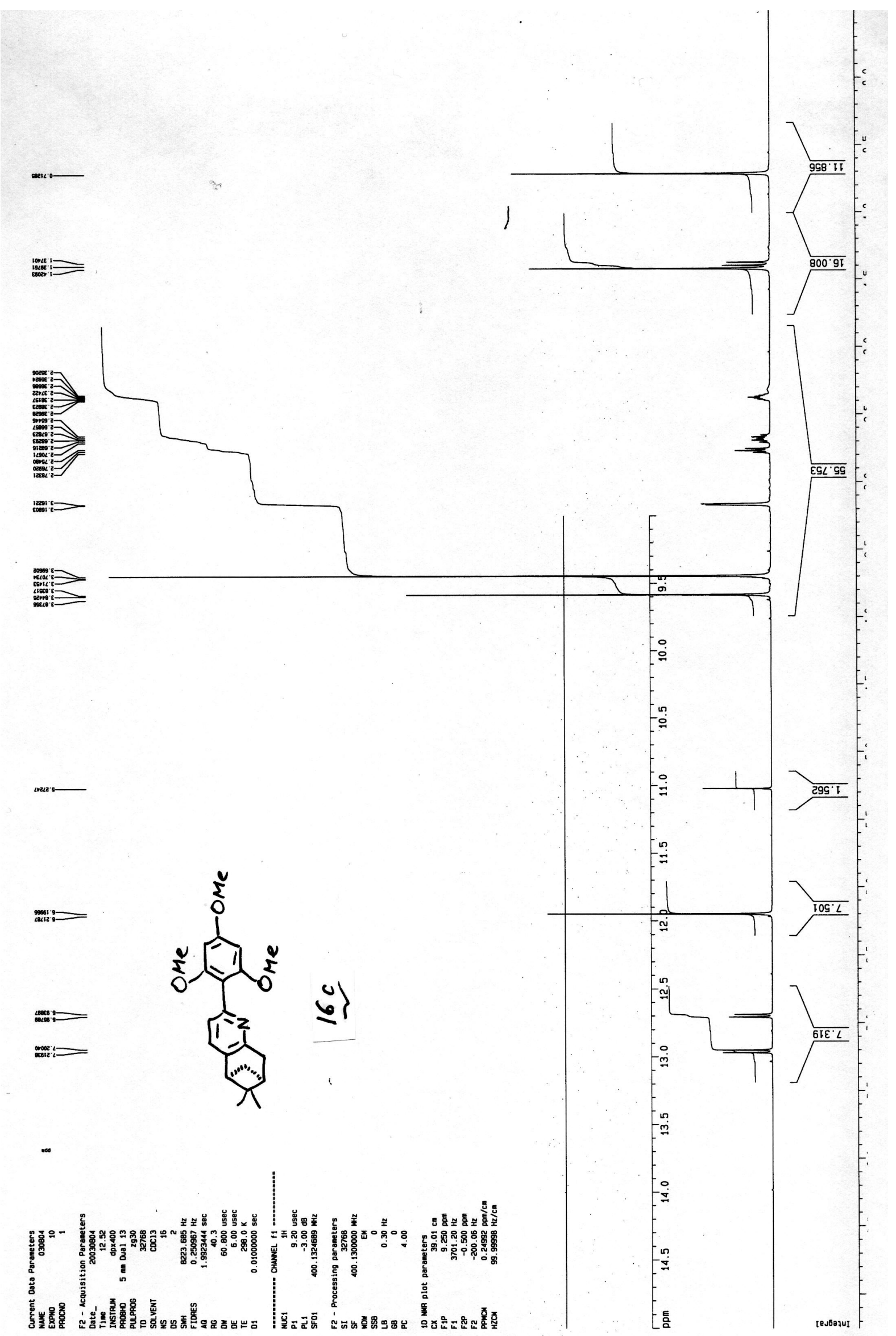


S(2) 11

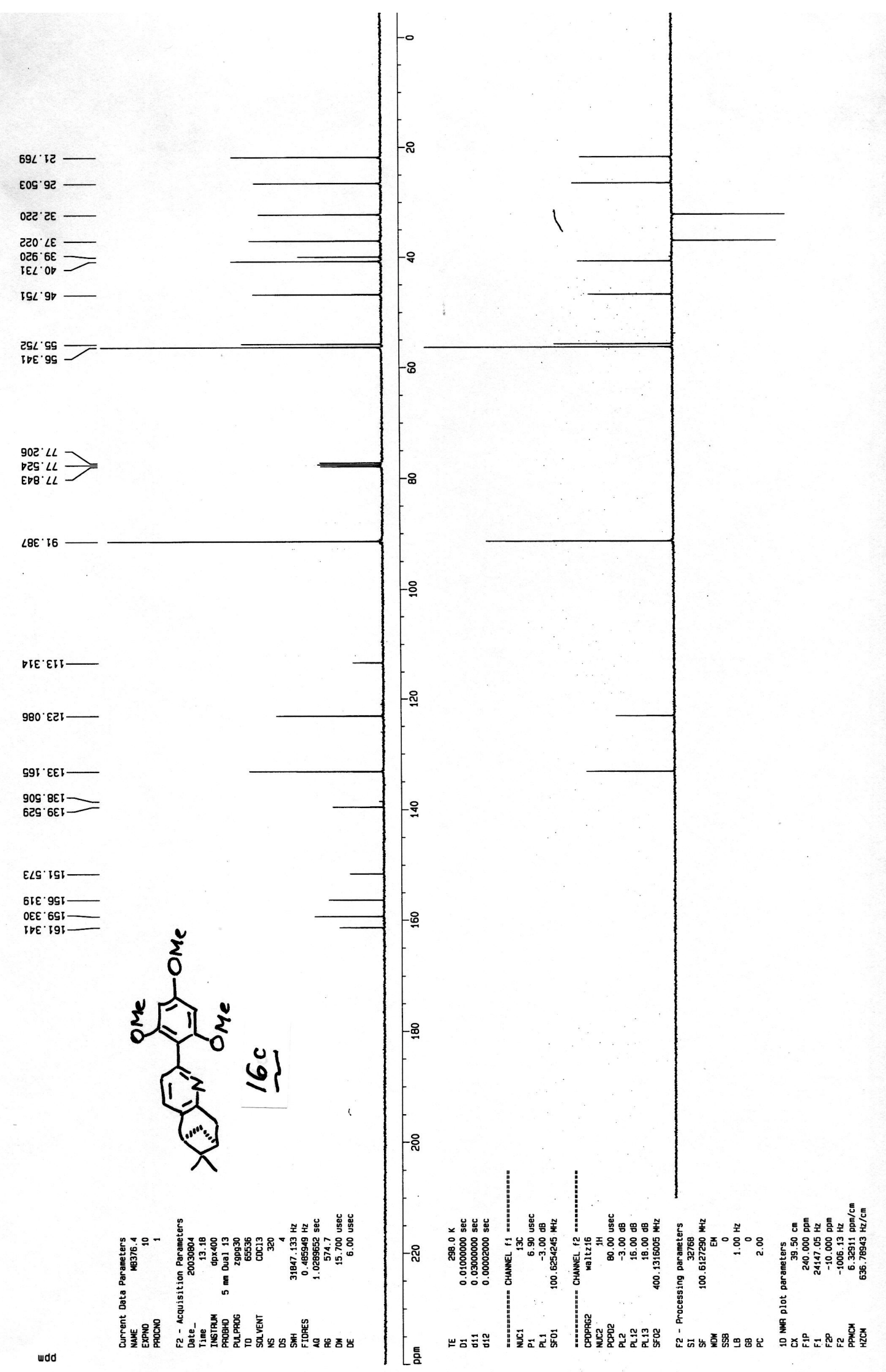


$\mathrm{S}(2) 12$

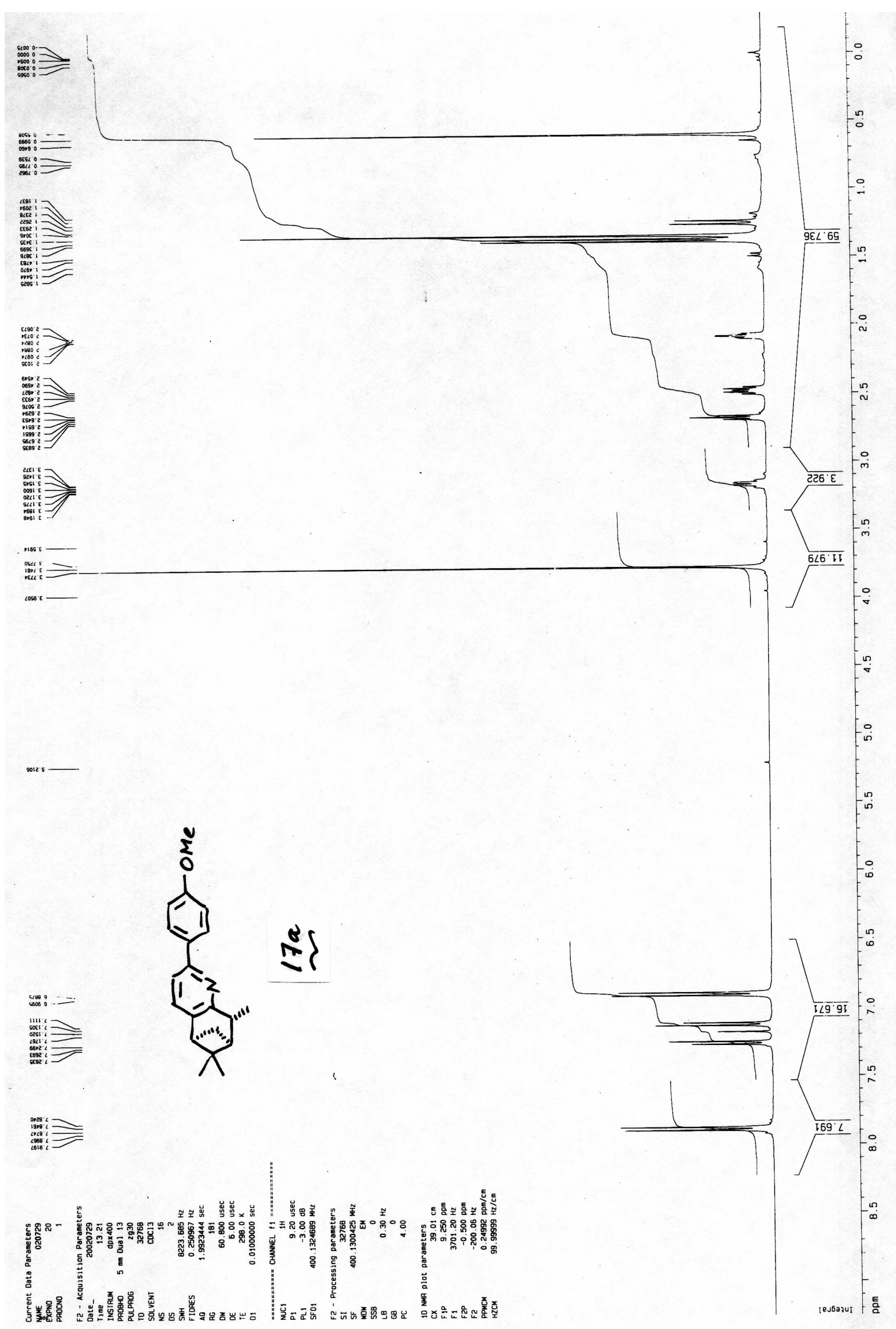


S(2) 13

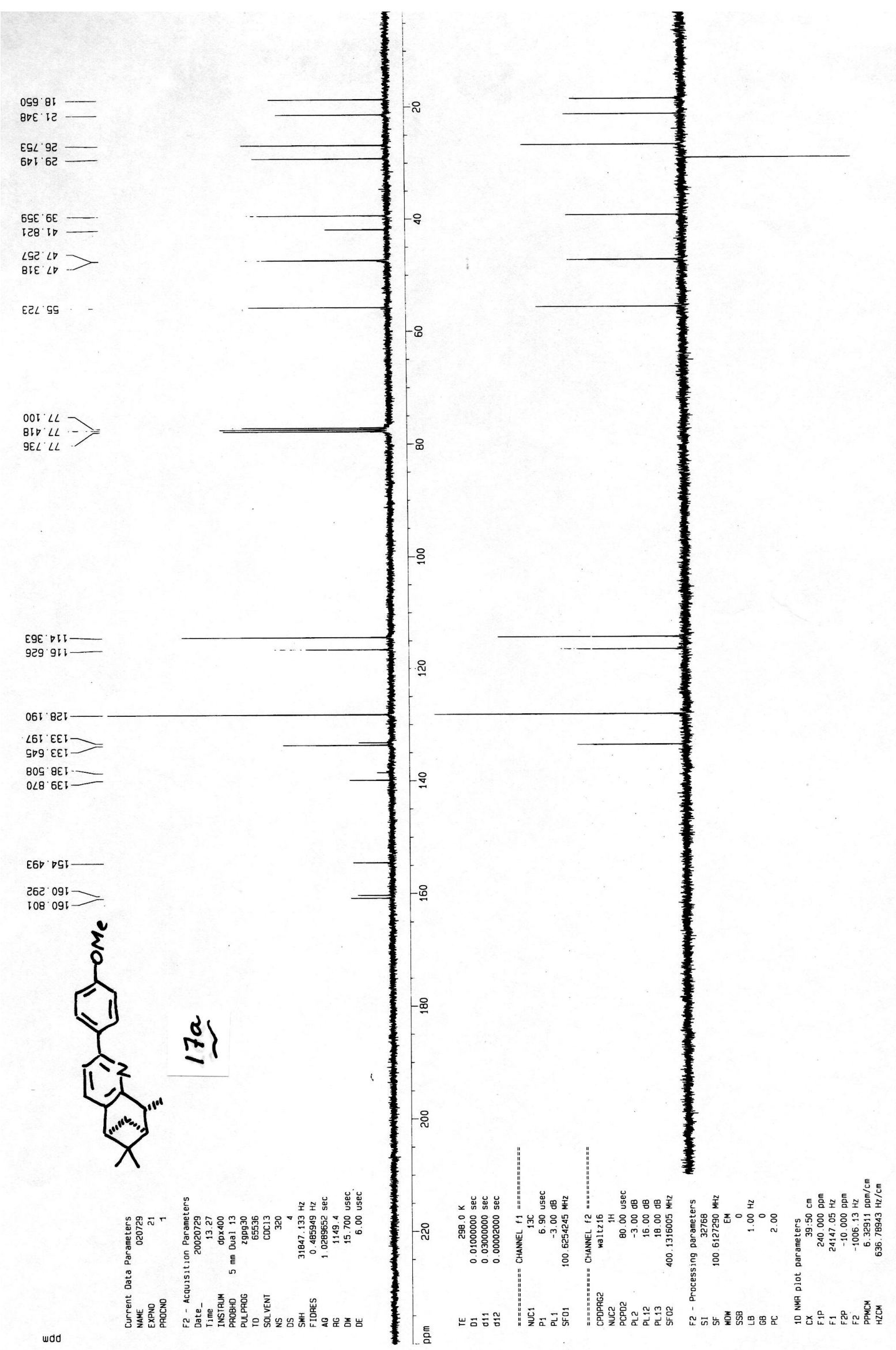


S(2) 14
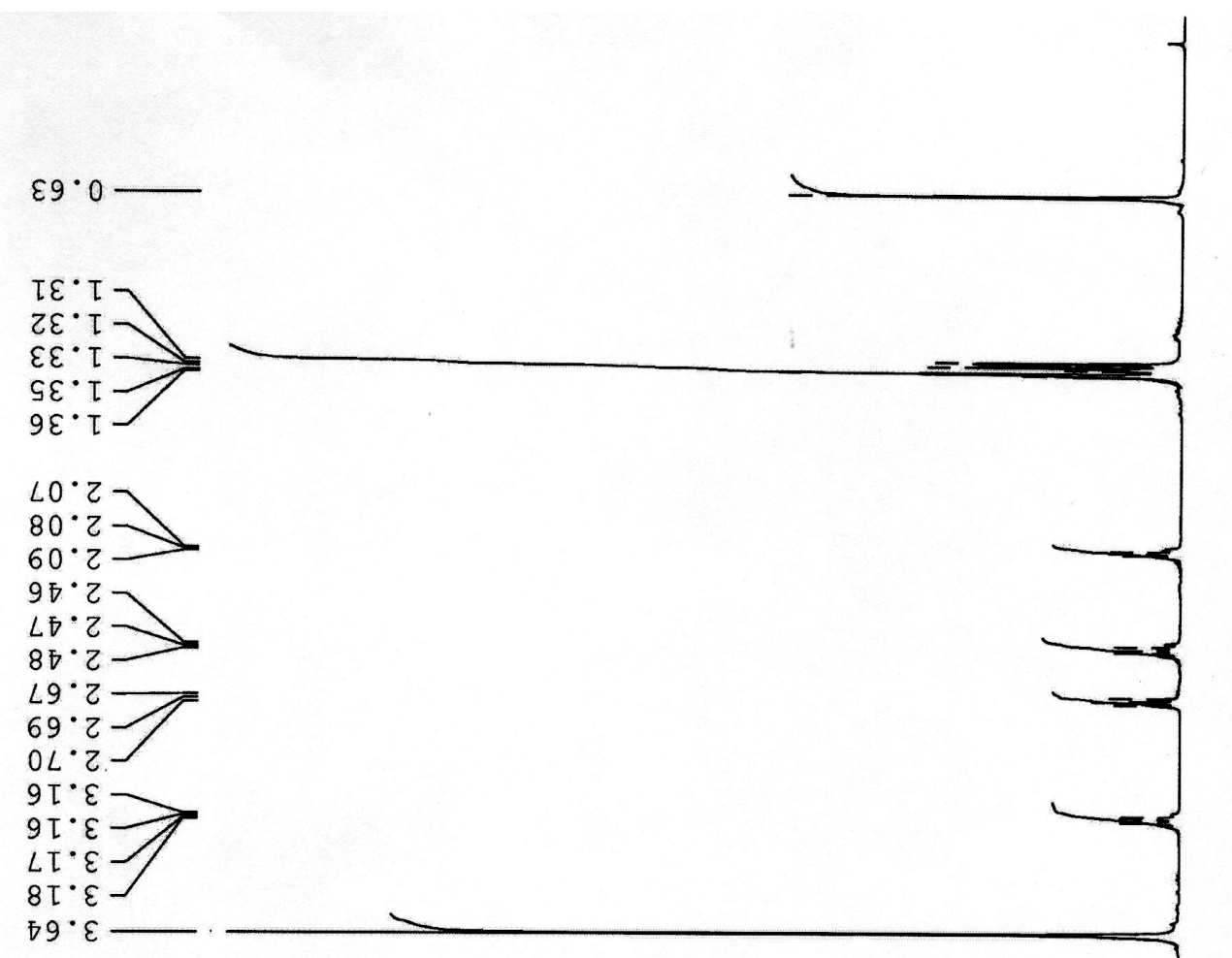

- \&

?

$\therefore \overline{260^{\circ} \varepsilon}$

$\circ$

$\overline{\mathrm{TOS} \cdot \mathrm{L}}$

4

ㅇ.

$220^{\circ}$

$\stackrel{\sim}{=\frac{060^{\circ} \tau}{0 \tau 0^{\circ} \tau}}$

$\stackrel{\circ}{m}$

$000^{\circ}$

$\nabla 9 \cdot \varepsilon$

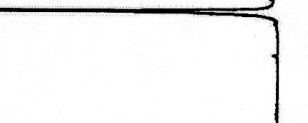

?

$8 \tau Z^{\circ} 9$

$\stackrel{\circ}{\circ}$

- ?

i

$\stackrel{0}{\circ}$

in

$\stackrel{0}{0}$
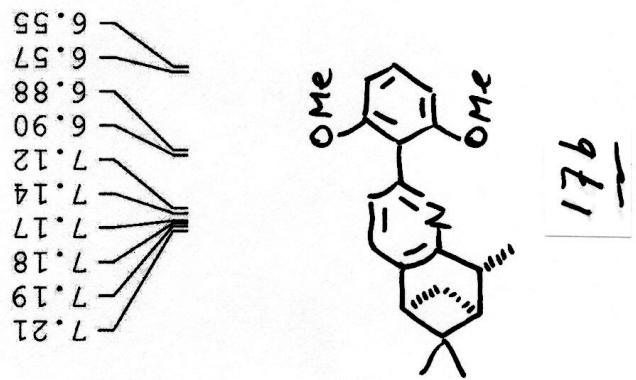

?

II0.2

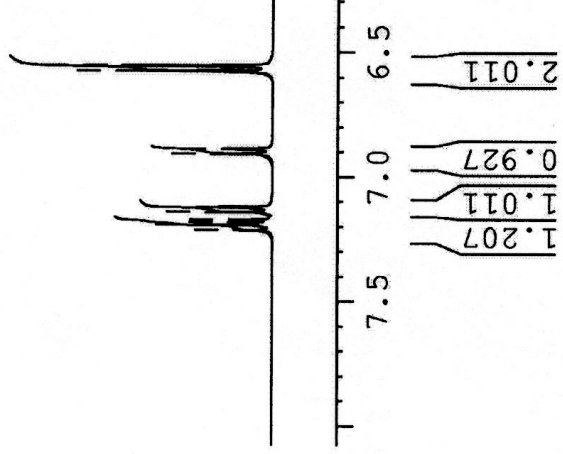


S(2) 15

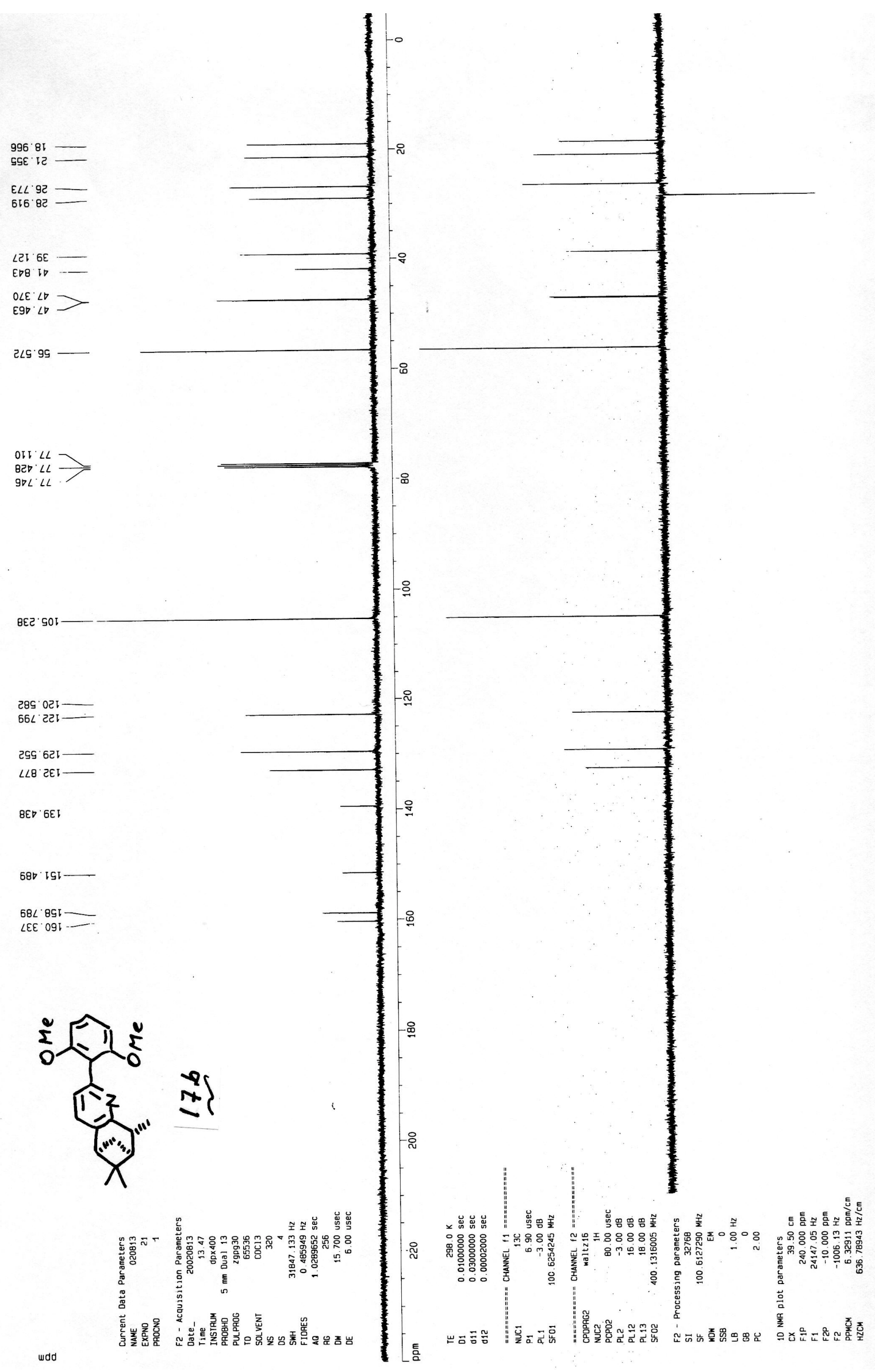


S(2) 16

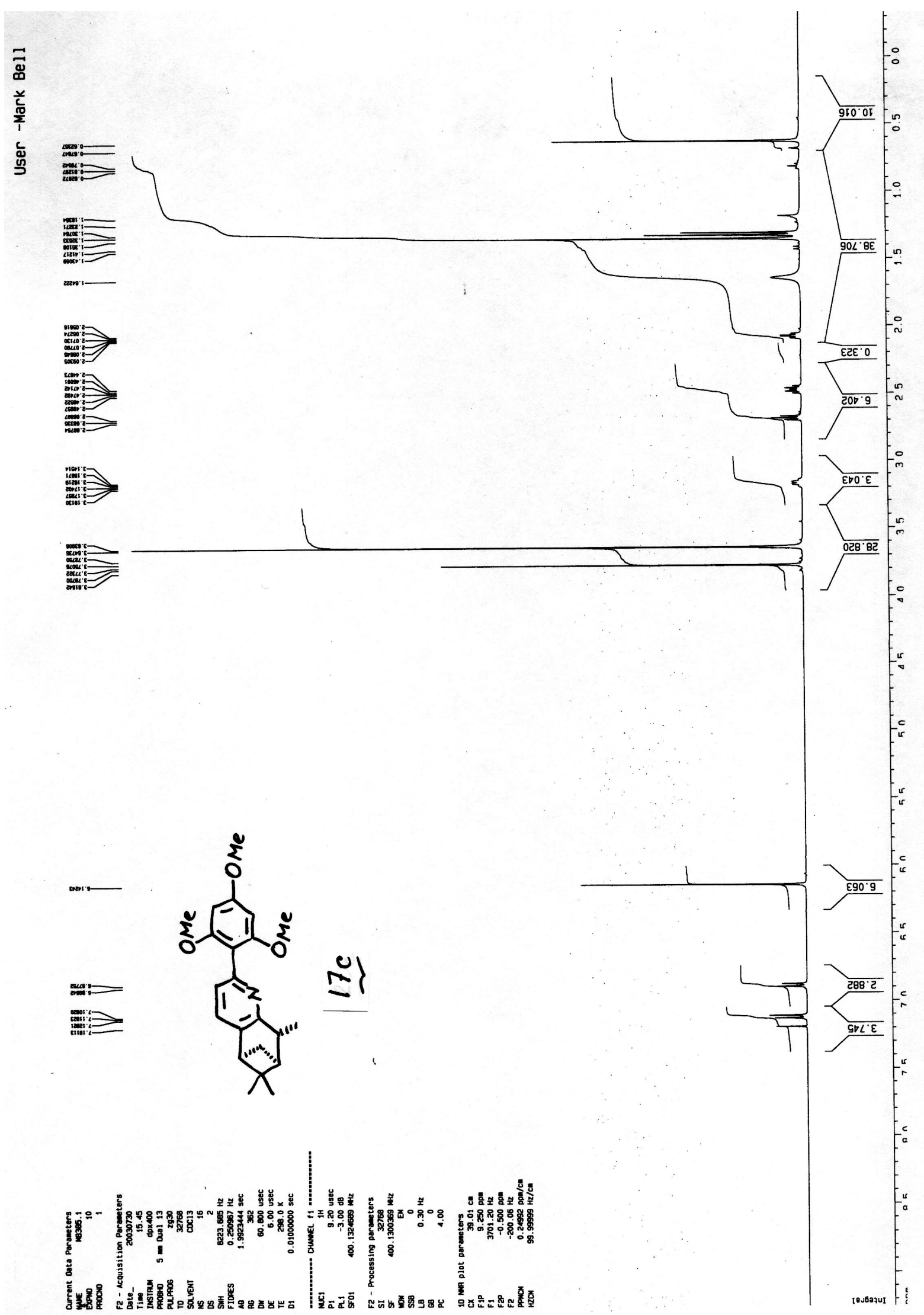


S(2) 17

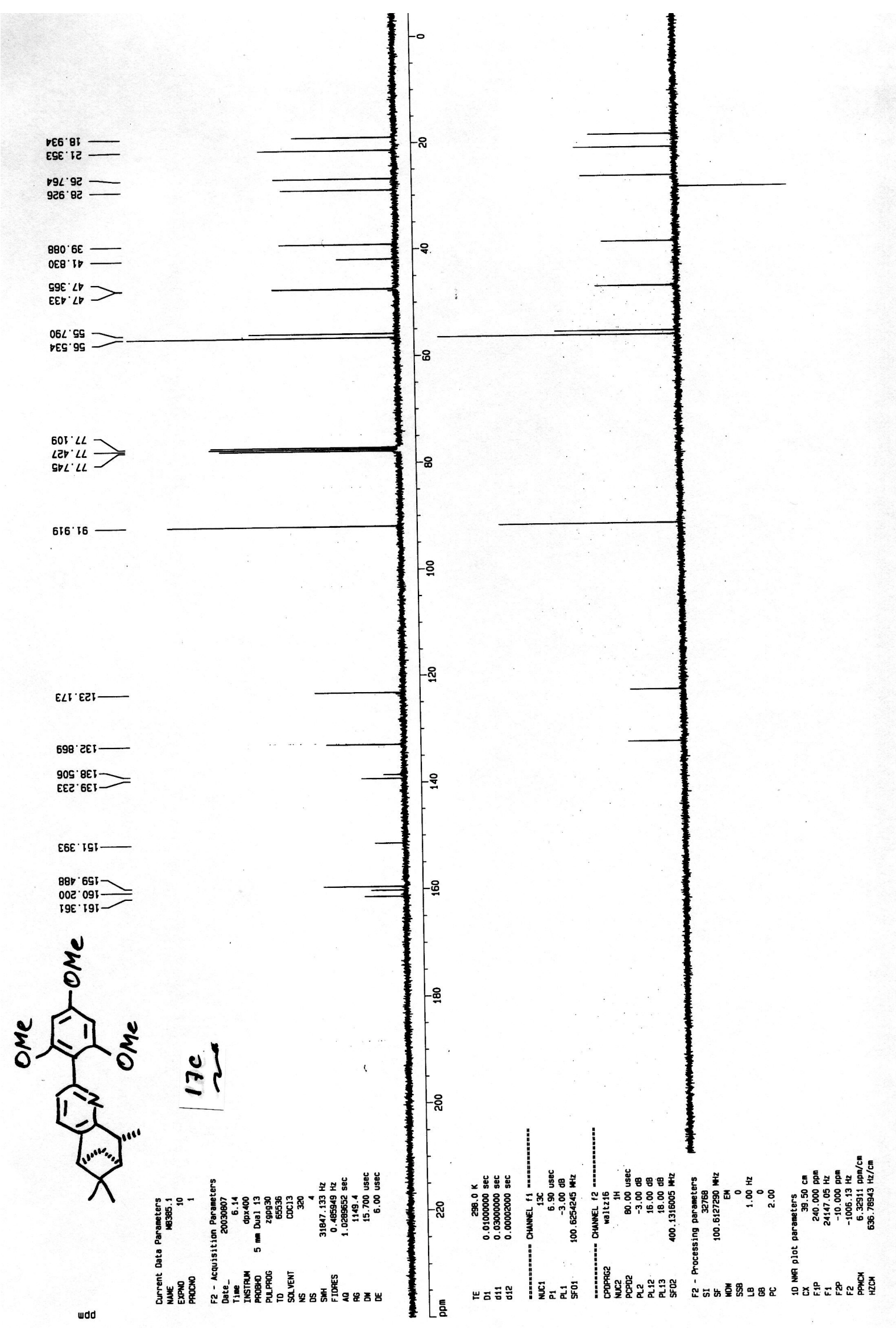

